\title{
Electrochemical Evaluation on Corrosion Behavior of SAF 2507 Duplex Stainless Steels in Blended Concrete with Metakaolin and ultrafine Slag Admixtures
}

\author{
Taoli Xiao ${ }^{1, *}$, Chenchen Dü, Yongle Liu ${ }^{3}$ \\ School of Urban Construction, Yangtze University, Jingzhou 434023, Hubei, China \\ *E-mail: 200536@yangtzeu.edu.cn
}

doi: $10.20964 / 2021.06 .15$

Received: 30 June 2020 / Accepted: 16 August 2020 / Published: 30 April 2021

\begin{abstract}
The supplementary cementitious materials can be used in the construction industry as a replacement of Portland cement (PC) to minimize the corrosion of steel rebar. In this work the effect of ultrafine slag (US) and metakaolin as partial replacement of PC on strength concrete and electrochemical corrosion behavior of SAF2507 duplex stainless steel (DSS) rebars were studied. The DSS reinforced concrete specimens were exposed to $3.5 \mathrm{wt} \% \mathrm{NaCl}$ solution. The mechanical results for concrete specimens indicated a considerable increase in compressive strength in the PC blended with both metakaolin and US (15M15US). The electrochemical results indicated that the 15M15US sample had higher value of corrosion resistance than the other samples. The surface morphologies of DSS rebars indicated that narrow pits and low production of corrosion were observed on the 15M15US sample which was in agreement with the results attained from electrochemical tests.
\end{abstract}

Keywords: Electrochemical corrosion; Supplementary cementitious materials; Duplex stainless steels; Mechanical properties

\section{$\underline{\text { FULL TEXT }}$}

(C) 2021 The Authors. Published by ESG (www.electrochemsci.org). This article is an open access article distributed under the terms and conditions of the Creative Commons Attribution license (http://creativecommons.org/licenses/by/4.0/). 